\title{
Primary amenorrhoea: a diagnostic dilemma
}

\author{
Deepika Narasegowda $^{1}$, Arun Kumar ${ }^{2}$, K. S. Aparna ${ }^{1}$ \\ ${ }^{1}$ Department of Obstetrics \& Gynaecology, Sri Devaraj Urs Medical College, Tamaka, Kolar-563101, Karnataka, India \\ ${ }^{2}$ Department of Obstetrics \& Gynaecology, Indira Gandhi Medical College, Shimla-171001, Himachal Pradesh, India
}

Received: 20 April 2015

Accepted: 09 May 2015

\section{*Correspondence:}

Dr. Deepika Narasegowda,

E-mail: deepikang@gmail.com

Copyright: ( $)$ the author(s), publisher and licensee Medip Academy. This is an open-access article distributed under the terms of the Creative Commons Attribution Non-Commercial License, which permits unrestricted non-commercial use, distribution, and reproduction in any medium, provided the original work is properly cited.

\begin{abstract}
Primary amenorrhoea is defined as absence of menses in females by the age of 14 years in the absence of secondary sex characters or absence of menses by the age of 16 years regardless of appearance of secondary sex characters. Incidence of Extrapulmonary TB (EPTB) is increasing in young women throughout the world. We report a case of 24 year unmarried female with primary amenorrhoea secondary to genital tuberculosis apparently having no sings \& symptoms of tuberculosis.
\end{abstract}

Keywords: Primary amenorrhoea, Genital tuberculosis

\section{INTRODUCTION}

Primary amenorrhoea is defined as:

1. No periods by age 14 in the absence of growth or development of secondary sexual characteristics.

2. No periods by age 16 regardless of the presence of normal growth and development with the appearance of secondary sexual characteristics. ${ }^{1}$

Incidence of primary amenorrhoea in gynaecological practice is less than $5 \% .^{2}$ Incidence of primary amenorrhoea due to genital tuberculosis is $2.5 \% .^{3}$ In approximately $50 \%$ of the patients with pelvic tuberculosis menstrual function is normal, while in about $25 \%$ the patient has menorrhagia. ${ }^{4}$ Amenorrhoea is the least common menstrual disturbance encountered in the disease. ${ }^{5}$ Such amenorrhoea is usually secondary. Very few cases of primary amenorrhoea caused by genital tuberculosis have been reported. Although pulmonary TB remains the commonest infectious type of $\mathrm{TB}$, extrapulmonary TB is being increasingly encountered specially in young women throughout the world. ${ }^{6}$

\section{CASE REPORT}

A 24 year old young female came to OPD in Indira Gandhi Medical College, Shimla with history of primary amenorrhoea. There is no history of prior medical consultation for the same. There is no past history of tuberculosis. On examination her vitals were stable, height $148 \mathrm{~cm}$, weight $42 \mathrm{~kg}$, BMI $19.17 \mathrm{~kg} / \mathrm{m}^{2}$. Secondary sexual characters: Breasts well developed (Tanner stage 5), axillary and pubic hair was normal (Tanner stage 5). On local examination, external genitalia was normal, on per rectal examination uterus was retroverted, normal size.

Routine blood investigations were normal. On buccal smear, barr bodies were present and karyotyping revealed normal female karyotype (46XX). ELISA test for HIV was negative. Her pelvic ultrasound and chest X-ray was normal. Serum FSH, LH, TSH and Prolactin were normal and serum estradiol was mildly elevated. She was given progesterone challenge test (oral medroxyprogesterone acetate $10 \mathrm{mg}$ for 5 days). Since she had no withdrawal bleed, estrogen progesterone challenge test was given which was also negative. Diagnosis of end organ problem 
was confirmed. Examination under anaesthesia with video endoscopic hysterolaparoscopy was planned.

On examination under anaesthesia, during per speculum examination cervix was unhealthy looking, erythematous, ulcerated, bleeds on touch, on per vaginal examination uterus was retroverted, normal size, adnexa nil palpable. On hysteroscopy, cavity was normal, there were no adhesions, both ostia normal, endometrium was blanched. Dialatation and curettage with cervical biopsy was done and endometrial curettings were obtained which was sent for histopathological examination, Ziehnl Neelsen staining and PCR.

On laparoscopy

- Bilateral beading seen on tubes with hydrosalpinx at fimbrial end.

- Flimsy adhesions were seen on posterior surface of uterus

- Evidence of straw coloured fluid (50 cc) in pouch of douglas

- No evidence of endometriotic spots seen.

- Uterus \& bilateral ovaries were grossly normal.

Ziehnl Neelsen staining of endometrial curettings revealed presence of acid fast bacilli suggestive of mycobacterium tuberculosis.

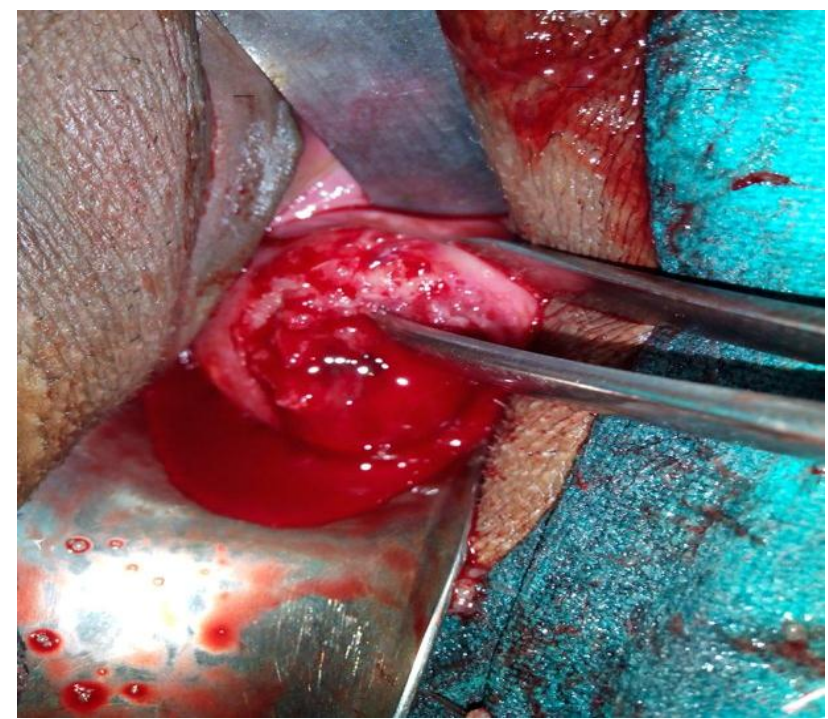

Figure 1: Per speculum showing ulcerated \& erythematous cervix.

Histopathological examination of endometrium revealed acute and chronic inflammatory cell infiltrate, epitheloid cell granulomas, Langhans type of giant cells along with endocervical glands infiltrated by inflammatory exudative material which confirmed the diagnosis of tuberculosis, Cervical biopsy revealed cervical glands lined by stratified squamous epithelium showing focal koilocytic change, cervical stroma showed infiltration by acute and chronic inflammatory cells, foreign body type of giant cells, scattered epithelioid cell granuloma and Langhans type of giant cells suggestive of tuberculous cervicitis.

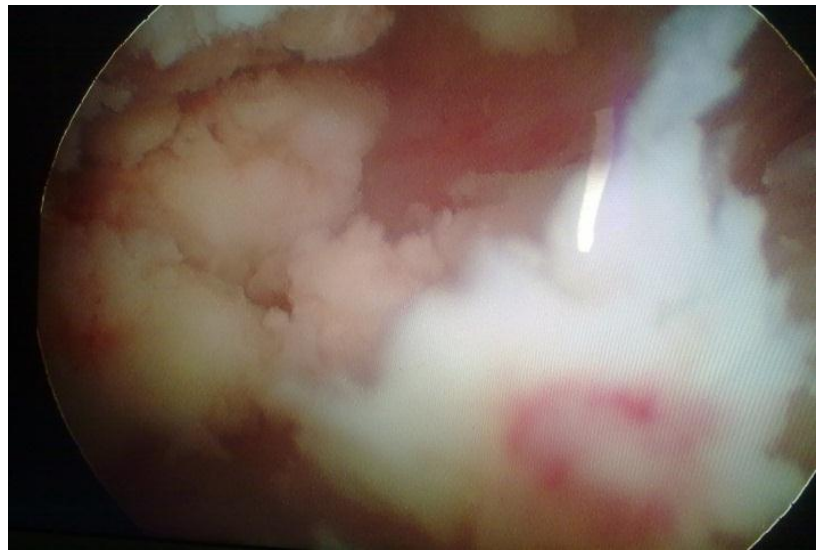

Figure 2: Hysteroscopic picture showing blanched endometrium with no adhesions.

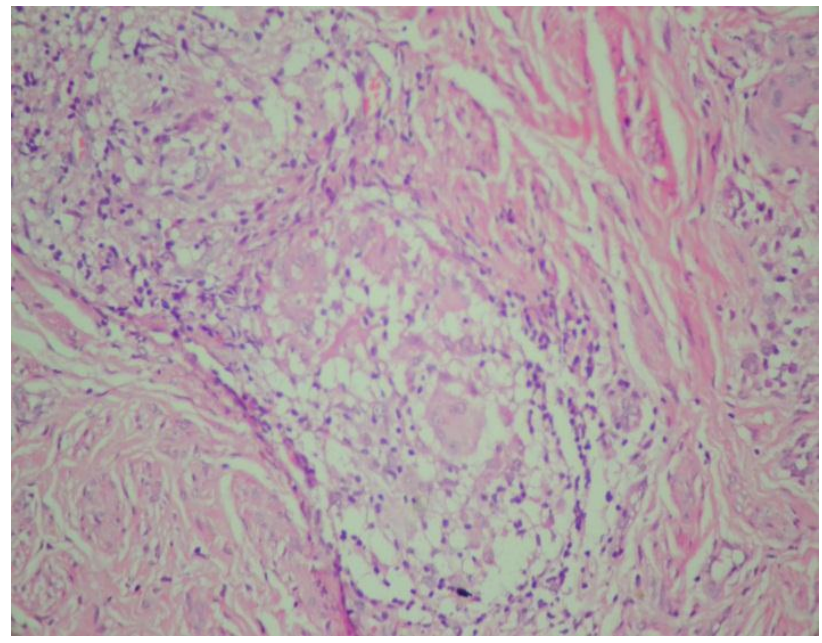

Figure 3: Histopathological picture of endometrium showing granulomatous lesion.

The patient was then started on antitubercular treatment under category 1 for 6 months. A repeat endometrial biopsy performed at the end of treatment showed resolution of granulomas. Patient resumed menses five months after initiation of antitubercular treatment.

\section{DISCUSSION}

The appropriate management of primary amenorrhoea will depend on the accurate diagnosis of etiology. A logical approach makes it possible to do it systematically and in shorter period of time. Genital tract TB is a chronic disease that often presents with low grade symptomatology and very few specific complaints. Presenting symptoms are generally varied: infertility 
being the most frequent clinical presentation (43-74\%). Other clinical presentations include oligomenorrhoea (54\%), amenorrhoea (14\%), menorrhagia (19\%), abdominal pain $(42.5 \%)$, dyspareunia (5-12\%), and dysmenorrhoea $(12-30 \%) .^{7}$ Other than primary amenorrhoea, there were no signs and symptoms of female genital TB in our case. For etiological diagnosis hysterolaparoscopy is an important investigation. Ultrasound has very limited role in the diagnosis of genital TB. ${ }^{8}$ Diagnosis depends upon the isolation of tubercle bacilli on microscopy and culture. Although presence of characteristic granuloma is sufficient to make the diagnosis. Fundamentally all the available molecular tests are based on the principle of polymerase chain reaction. PCR is a rapid, sensitive and specific molecular biological method applied in the laboratories to diagnose multitudes of diseases. PCR based diagnosis of TB has been evaluated to be useful and important in the detection of pulmonary as well as extrapulmonary TB.

Hence there is a role of methodological approach in investigating a case of primary amenorrhoea. Multiple drug treatment in adequate doses and duration is the main stay of treatment including genital TB. Short course chemotherapy has been found to be useful for genital TB.

\section{CONCLUSION}

Primary amenorrhoea is an important gynaecological, endocrinological condition. Compartment wise diagnosis is made by proper methodological approach. The incidence of genital $\mathrm{TB}$ is rising. This represents a challenging clinical problem in terms of diagnosis, assessment of the extent of damage caused by the disease and treatment of the consequences.

This case report illustrates that genital TB should always be considered as potential cause of primary amenorrhoea, especially in patients from countries with high prevalence of TB, even in the absence of previous history of TB.

Funding: No funding sources

Conflict of interest: None declared

Ethical approval: Not required

\section{REFERENCES}

1. Speroff L, Glass RH, Kase NG. Amenorrhoea. In: Mitchell C, eds. Clinical Gynaecologic Endocrinology and Infertility. 5th ed. Baltimore: William and Wilkins; 1994: 401-456.

2. Wachtel SS. The genetics of intersexuality: clinical and theoretic perspectives. Obstet Gynaecol. 1979;54:671-83.

3. Rao K, Pillai NV. Primary amenorrhoea (analysis of 40 cases). J Indian Medi Assoc. 1991;89:42-3.

4. Stallworthy J. Amenorrhoea. In: Stallworthy J, eds. British Gynaecological Practice. 2nd ed. London: Heinemann; 1958: 559.

5. Liljedahl SO, Ryden ABV. Diagnosis and treatment of genital tuberculosis in women. Acta Obstet Gynecol Scand. 1951;30:359-83.

6. Kumar S. Female genital tuberculosis. In: Sharma SK, Mohan A, eds. Tuberculosis. 2nd ed. Delhi: Jaypee; 2009: 441-448.

7. Gatongi DK, Gitau G, Kay V, Ngwenya S, Lafong C, Hasan A. Female genital tract tuberculosis. Obstet Gynaecol. 2005;7:75-9.

8. Sharma JB. Tuberculosis and obstetric and gynaecological practice. In: Studd J, Tan SL, Chervenak FA, eds. Progress in Obstetrics and Gynaecology. 1st ed. Philadelphia: Elsevier; 2008: $395-427$.

DOI: 10.18203/2320-1770.ijrcog20150131

Cite this article as: Narasegowda D, Kumar A, Aparna KS. Primary amenorrhoea: a diagnostic dilemma. Int $\mathbf{J}$ Reprod Contracept Obstet Gynecol 2015;4:924-6. 